\title{
Debating late abortion: time to tell the truth
}

Ellie Lee

\section{Background}

No one can have escaped the recent media interest in abortion. A striking aspect of the discussion so far has been the role of those who have provoked the debate by arguing for a reduction in the legal time limit for abortion, yet who describe themselves as 'pro-choice'. Professor Stuart Campbell, the obstetrician who runs a London clinic that provides four-dimensional ultrasound images to women during pregnancy, contends he is a firm supporter of legal abortion, but has been arguing for an upper limit of 18 weeks, with 12 weeks for 'social abortion'.1 American feminist Naomi Wolf has concluded that the current 24 week time limit is 'too generous'.2 Sir David Steel, architect of the 1967 Abortion Act, has made the most significant intervention, contending the limit should be 22 weeks, with 12 weeks for most abortions. ${ }^{3}$ The apparent wish on the part of opinion from this quarter to reopen the time limits discussion suggests the debate may gain further momentum.

Steel's proposals are most specific. His case is as follows. First, that late abortion can be prevented if abortion is available "as early as possible", and that the current 'two doctors' requirement "has led in some cases to delay". Thus the law should be changed to provide for abortion 'on request' in the first 3 months of pregnancy. Second, the abortion law must be shaped by changes in technology. Since the 1967 Abortion Act was passed, "medical science has continued to advance, recording survivals at 22 weeks of pregnancy, and lurid publicity has been given to "botched' abortions", he argues. So the upper limit should be reduced. It is not clear what he thinks should happen if the woman is 13-22 weeks' pregnant (or what should happen where serious fetal abnormality is diagnosed). But his implication is that that after 12 weeks abortion would be not illegal; however, access would be restrictive. I would encourage people to question such arguments and consider the following issues.

\section{Why women terminate pregnancies in the second trimester}

About 22000 women each year have an abortion after 12 weeks, 2500 of whom abort at 20-24 weeks. The most important issue to address is why these women have abortions when they do.

Evidence suggests it is in fact wrong to believe that these women experience delays or lack of access to firsttrimester procedures. In truth, in most cases - available evidence suggests at least $80 \%$ - they did not realise they needed to request abortion until they were more than 3-4 months' pregnant. ${ }^{4,5}$ This is the case for women for whom the fetus is found, through routine screening, to be abnormal. The experience of two other groups of women is less well recognised.

\section{J Fam Plann Reprod Health Care 2005; 31(1): 7-9}

School of Social Policy, Sociology and Social Research, University of Kent, Canterbury, UK

Ellie Lee, BSc, PhD, Lecturer in Social Policy, and Pro-Choice Forum Co-ordinator

Correspondence to: Dr Ellie Lee, School of Social Policy, Sociology and Social Research, Cornwallis NE, University of Kent, Canterbury CT2 7NF, UK. E-mail: E.J.Lee@kent.ac.uk
First, there are women who fail to realise they are pregnant earlier because of irregular, infrequent periods; failed contraception (particularly with methods that can cause amenorrhoea or irregular bleeding); and denial of pregnancy (sometimes associated with occasional episodes of bleeding that are interpreted as menstruation). Second, some women delay seeking abortion because of indecision (ambivalence about the pregnancy); apprehension (difficulty in confiding in parents or partner); failure of anticipated emotional or economic support (from family, partner and employer); and unanticipated change in socioeconomic circumstances (with her partner, parents or others dependent on her as a carer).

A study of the experience of young women 6 indicates how some of these factors result in second-trimester abortions. As one young woman, aged 17 years, who had an abortion at 20 weeks explained:

"I started on the pill about the end of August ... I'd never been on the pill before ... I didn't know what to expect.... When I'd been to the GP I'd worked out I was two months pregnant ... then I went in to have the internal examination [at the consultation for pregnancy termination] ... he was like, 'well actually ... you're more like four and a half months pregnant' ... I hadn't known, 'cause I hadn't been having my periods normally."

Another young woman, also aged 17 years, knew she was pregnant at 8 weeks, but had an abortion at 19 weeks:

"I told my partner ... he seemed all right with it as well. But then I started getting mixed feelings about whether or not I should keep it and I started coming up with all the reasons in my head ... it's from there it started to change."

An ongoing research project ('Young Women's Experience of Abortion in the Second Trimester' at the Centre for Sexual Health Research, University of Southampton, Southampton, UK), which includes interviews with staff working for abortion providers, highlights another aspect of women's experience:

"A recent one, that was a planned pregnancy, was very much wanted. She was about 23 weeks. And her husband said he was leaving her for her best friend. She just couldn't continue. She just couldn't have his baby. She just wept and wept and wept."

There is a fourth category of women, namely those who do experience difficulty in accessing abortion. The general practitioner is unwilling to refer; the local National Health Service (NHS) services are inadequate (long waits for assessment and treatment); the local NHS service does not terminate under Ground $C$ after 12 weeks; and/or the woman is unable to afford treatment in the independent sector.

How would current proposals affect women such as these? In most cases they would not, as Lord Steel suggests, have early abortions because, for reasons beyond their control, they did not seek abortion until later. Making access harder after 12 weeks would likely have made them abort later still, or they would have had babies they did not want. Those who argue for restrictions to late abortion need to address this reality.

\section{The extent of technological development}

It is becoming something of a given that technological developments should make us rethink the abortion law. But 
this is a misrepresentation of the situation. The prospects for premature babies are far better than in 1967. But they are still very poor.

Those babies born in Great Britain and Ireland have survival rates of $0 \%$ at 21 weeks, and about $1 \%$ at 22 weeks, $11 \%$ at 23 weeks and $26 \%$ at 24 weeks. ${ }^{7}$ The EPICure Study (the most recent study of UK and Irish premature birth outcomes) found that of 865 live births of up to 24 weeks' gestation recorded in the UK and Ireland between March and December 1995, 47\% died in the delivery room and $38 \%$ died in neonatal intensive care units. Some $15 \%$ of all the survivors in the study were able to leave hospital; however, a further $0.3 \%$ of these died at home afterwards.7,8 There is no clear evidence that there has been any reduction in long-term disability among the survivors of infants born at 24 weeks or more. Indeed, rates of severe disability in the long term are $25 \%$. 9

The argument that advances in technology clearly make the current limit outdated is, therefore, dishonest. It is to be hoped, however, that the situation for premature babies improves. We need, in this light, to consider the problems of an approach which suggests that technological advances that assist one group of pregnant women (those with wanted pregnancies who deliver early) should imply a diminishment of choice, and the ability to control their lives, for another (those with unwanted pregnancies). Surely we can welcome improvements in premature baby survival rates without having to force women seeking abortion to continue their pregnancies? Do we really want an abortion law that rests on the assumption this cannot be the case?

\section{The emotional response}

The third problem with current arguments is that they pander to irrational and confusing views. The time limit should come down, it is claimed, in response to stories about 'botched abortions' in the NHS, where a fetus is seen to move following the performance of a late abortion. There are important issues requiring clarification here.

In the vast majority of cases where it is necessary to stop the fetal heart, and thus prevent the possibility of a fetus showing signs of life after an abortion, this is done effectively and efficiently (the Royal College of Obstetricians and Gynaecologists recommends feticide from 21 weeks onwards, by the injection into the fetal heart of potassium chloride or by the intra-amniotic injection of concentrated urea). ${ }^{10}$ The fact that there are a small number of cases where feticide has failed requires not moral panic about 'botched abortions', but serious discussion about how best to provide a better late abortion service.

Staff must have special training and a caseload that is sufficient to maintain their skills. Yet most NHS gynaecological units now handle only a small number of abortions over 20 weeks $(75 \%$ are now performed by independent sector clinics). There is a need, in this light, to consider how late abortion services should be provided, and how training should be managed. Simply proposing banning late abortion confuses matters and ignores the relevant issues.

It is equally important to question the highly emotional case against late abortion made on the basis of fourdimensional images of fetuses apparently 'walking' and 'crying' in utero at 13-17 weeks. Telling the truth is essential here, and the truth is that fetuses are not like a year-old baby 'in miniature'. While they move and exhibit reflex reactions, they are biologically undeveloped and most certainly not sentient or self-aware. It helps no one when such false impressions about the fetus are allowed to hold sway.

It is important that society debates its abortion laws. But it is to be hoped that more honesty about the relevant issues will emerge from now on. Above all, the truth should be told about the inescapable practical effect of a lower time limit. A larger number of women than is currently the case will either have to continue an unwanted pregnancy and give birth, or seek abortion in another country.

Statements on funding and competing interests

Funding. None identified.

Competing interests. None identified.

References

1 Viewpoints: abortion. http://news.bbc.co.uk/1/hi/health/3894245.stm [Accessed 20 September 2004].

2 Naomi Wolf. Face to face with a horrible truth. Sunday Times, 11 April 2004.

3 David Steel. We need to rethink my abortion law. The Guardian, 6 July 2004

4 George A, Randall S. Late presentation for abortion. Br J Fam Plann 1996; 22: 12-15.

5 Royal College of Obstetricians and Gynaecologists (RCOG). Late Abortion in England and Wales: Report of a National Confidential Study, Alberman E, Dennis KJ (eds). London, UK RCOG Press, 1984. See also http://www.guttmacher.com/pubs/ab_slides.html [Accessed 20 September 2004].

6 Lee E, Ingham R, Clements S, Stone N. A Matter of Choice? National Variation in Teenage Pregnancy, Abortion and Motherhood. York, UK: Joseph Rowntree Foundation, 2004

7 Costeloe K, Hennesy E, Gibson, AT. The EPICure Study: outcomes to discharge from hospital for infants born at the threshold of viability. Pediatrics 2000; 106: 659-671.

8 Wood NS, Costeloe K, Gibson AT, Hennessy EM, Marlow N, Wilkinson AR and the EPICure Study Group. The EPICure Study: growth and associated problems in children born at 25 weeks of growth and associated problems in children born at 25 weeks of gestational age

9 Premature babies' disability risk. http://news.bbc.co.uk/1/hi/health/ 3666068.stm [Accessed 20 September 2004].

10 Royal College of Obstetricians and Gynaecologists (RCOG). Termination of Pregnancy for Fetal Abnormality in England, Wales and Scotland. London, UK: RCOG Press, 1996.

\title{
NOTES FOR CONTRIBUTORS
}

\author{
The latest version of the Journal's Notes for Contributors can be found on the \\ Faculty website at www.ffprhc.org.uk. The electronic notes are reviewed \\ regularly and updated as required.
}

J Fam Plann Reprod Health Care 2005: 31(1) 